\title{
Clinical Presentation, Diagnosis, and Management of Idiopathic Enlargement of the Right Atrium: An Analysis Based on Systematic Review of 153 Reported Cases
}

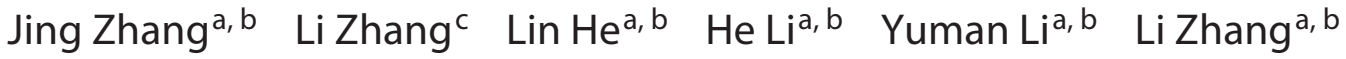 \\ Mingxing $\mathrm{Xie}^{\mathrm{a}, \mathrm{b}}$ \\ aDepartment of Ultrasound, Union Hospital, Tongji Medical College, Huazhong University of Science and \\ Technology, Wuhan, China; ${ }^{b}$ Hubei Province Key Laboratory of Molecular Imaging, Wuhan, China; ${ }^{\circ}$ Department of \\ Thoracic and Cardiomacrovascular Surgery, Shiyan Taihe Hospital Affiliated to Hubei University of Medicine, Shiyan, \\ China
}

\section{Keywords \\ Idiopathic enlargement of the right atrium - Arrhythmia . \\ Echocardiography · Surgical resection}

\begin{abstract}
Idiopathic enlargement of the right atrium (IERA) is a rare cardiac anomaly, and only sporadic cases have been reported. Little is known about its clinical relevance, and inconsistencies in medical and surgical management remain among different settings. In this paper, we systematically reviewed the published cases of the IERA in terms of clinical presentation, diagnosis, and management. A total of 153 cases of IERA were covered. Arrhythmia, dyspnea, and palpitation were found to be the most common clinical manifestations. It tends to be associated with life-threatening complications and sudden cardiac death. Diagnosis was mostly established by using echocardiography. Presenting symptoms, abnormal ECG findings, and therapeutic modalities were significantly related to the prognosis of IERA. Symptomatic patients were significantly more likely to have poor outcomes than asymptomatic patients $(p=0.044)$, and conservative treatment was more associated with adverse outcomes compared to surgical resection ( $p=0.016)$. In conclusion,
\end{abstract}

IERA, although rare, tends to be associated with potential life-threatening complications and sudden cardiac death. Echocardiography is the most common diagnostic modality. Surgical resection is indicated for symptomatic patients.

(c) 2020 S. Karger AG, Base

\section{Introduction}

Idiopathic enlargement of the right atrium (IERA) represents a rare cardiac anomaly, characterized by an isolated enlargement of the right atrium (RA) in the absence of additional cardiac lesions causing RA dilatation [1]. The embryology and pathophysiology of this rare entity are poorly understood. Although this condition is asymptomatic in most cases, some cases might present with arrhythmias, airway obstruction, heart failure, and thromboembolic events [1-4]. The mortality of the condition reportedly stood somewhere at $5 \%[5,6]$. However, studies on its clinical features, diagnosis, treatment, and prognosis are limited, without consensus about its management, including prophylactic aneurysmal resection and the conservative treatment, since only sporadic cases were reported. In this study, on the basis of an extensive karger@karger.com

www.karger.com/crd

Karger $\stackrel{2}{*}$ (c) 2020 S. Karger AG, Base 
Table 1. Demographic and clinical characteristics of the study subjects $(n=153)$

\begin{tabular}{|c|c|c|c|c|c|}
\hline & $\begin{array}{l}\text { Total } \\
(n=153)\end{array}$ & $\begin{array}{l}\text { Children group } \\
(n=70)\end{array}$ & $\begin{array}{l}\text { Adult group } \\
(n=83)\end{array}$ & $\chi^{2}$ & $p$ valve \\
\hline Age, years & $25.17 \pm 23.26$ & $4.56 \pm 5.38$ & $42.83 \pm 17.37$ & & \\
\hline \multicolumn{6}{|l|}{ Gender, $n(\%)$} \\
\hline Male & $90(58.82)$ & $39(55.71)$ & $51(61.45)$ & 0.107 & 0.744 \\
\hline Female & $47(30.72)$ & $19(27.14)$ & $28(33.73)$ & & \\
\hline Unknown & $16(10.46)$ & $12(17.14)$ & $4(4.82)$ & & \\
\hline \multicolumn{6}{|l|}{ Complaints, $n(\%)$} \\
\hline Antenatal & $30(19.61)$ & $29(41.43)$ & $1(1.20)$ & 38.992 & 0.000 \\
\hline Incidental finding & $50(32.68)$ & $17(24.29)$ & $33(39.76)$ & & \\
\hline Symptoms & $73(47.71)$ & $24(34.29)$ & $49(59.04)$ & & \\
\hline Symptoms, $n(\%)$ & $89(58.17)$ & $37(52.86)$ & $52(62.65)$ & & \\
\hline Arrhythmia & $50(32.68)$ & $22(31.43)$ & $28(27.71)$ & 1.497 & 0.221 \\
\hline Dyspnea & $31(20.26)$ & $13(18.57)$ & $18(21.69)$ & & \\
\hline Palpitation & $29(18.95)$ & $9(12.86)$ & $20(24.10)$ & & \\
\hline Edema & $11(7.19)$ & $2(2.86)$ & $9(10.84)$ & & \\
\hline Chest discomfort/pain & $10(6.54)$ & $0(0)$ & $10(12.05)$ & & \\
\hline Fatigue & $9(5.88)$ & $2(2.86)$ & $7(8.43)$ & & \\
\hline Abnormal ECG, $n(\%)$ & $77(50.33)$ & $30(42.86)$ & $47(56.63)$ & & \\
\hline SVT & $30(19.61)$ & $16(22.86)$ & $14(16.87)$ & 2.880 & 0.090 \\
\hline Atrial flutter/fibrillation & $35(22.88)$ & $10(14.29)$ & $25(30.12)$ & & \\
\hline $\mathrm{RBBB}$ & $11(7.19)$ & $4(5.71)$ & $7(8.43)$ & & \\
\hline Other & $8(5.23)$ & $5(7.14)$ & $3(3.61)$ & & \\
\hline Complication, $n(\%)$ & $86(56.21)$ & $33(47.14)$ & $53(63.86)$ & & \\
\hline Arrhythmia/tachycardia & $77(50.33)$ & $30(42.86)$ & $47(56.63)$ & 4.309 & 0.038 \\
\hline Embolism & $16(10.46)$ & $5(7.14)$ & $11(13.25)$ & & \\
\hline RHF & $11(7.19)$ & $3(4.29)$ & $8(9.64)$ & & \\
\hline Sudden cardiac death & $4(2.61)$ & $2(2.86)$ & $2(2.41)$ & & \\
\hline TR & $6(3.92)$ & $4(5.71)$ & $2(2.41)$ & & \\
\hline RA wall dissection & $1(0.65)$ & $1(1.43)$ & $0(0)$ & & \\
\hline
\end{tabular}

SVT, supraventricular tachycardia; RBBB, right bundle branch block; RHF, right heart failure; TR, tricuspid regurgitation; RA, right atrium.

and intensive search of literature, we systematically reviewed the published literature on IERA for its demographics, clinical characteristics, diagnosis, treatment, and prognosis, to understand its clinical features for development of better management strategies.

\section{Methods}

The IERA was referred by different terms in the literature, such as idiopathic enlargement, dilation of the RA, giant right atrial aneurysm or right atrial diverticulum, and right atrial appendage aneurysm [1, 7-9]. Their presentations, however, virtually overlapped on different imaging modalities, including histological analysis. Moreover, their clinical presentations, treatment strategies, and prognosis were essentially identical. Thus, these terms have been used interchangeably in the literature. For better understanding of IERA, we conducted a comprehensive review including most articles, though it was described by different names.
Medline, Pubmed, and EMBASE were electronically searched for case reports, case series, and related articles regarding IERA published as of August 2019. The keywords for literature retrieval included "right atrial aneurysm," "idiopathic dilatation of the RA," "congenital enlargement of the RA," "right atrial appendage aneurysm," or "right atrial diverticulum." The search was restricted to human studies published in English. Articles without data of individual cases and duplicate reports were eliminated. In addition, cases with possible secondary causes of RA enlargement, such as atrial septal defects, anomalous pulmonary venous return, Ebstein's anomaly, and other lesions of the tricuspid or pulmonary valve were excluded. The data recorded were (1) clinical data covering age, gender, complaints, symptoms and signs, and findings of physical checkups; (2) diagnostic methods and findings; (3) morphological features; (4) treatment options and outcomes; (5) the results of autopsy and histology; and (6) follow-ups and prognosis.

All statistical analyses were performed by using SPSS software package (version 23.0, SPSS, Inc, Chicago, IL, USA). Continuous variables were expressed as mean \pm standard deviation and categorical variables as frequencies and percentages $(n, \%)$. To exam- 
Fig. 1. Patients' age profile of the idiopath-

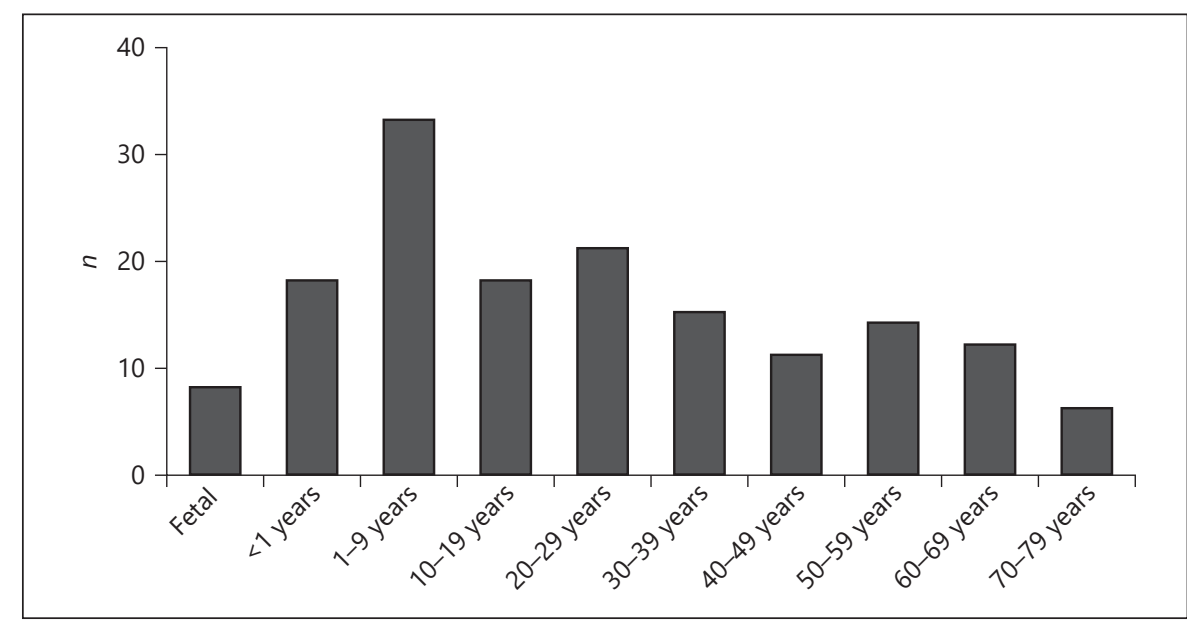
ic enlargement of the right atrium.

ine the effect of age, the subjects were divided into 2 groups: $<18$ years group (child group) and $\geq 18$ years group (adult group). Continuous variables were compared between the groups by employing Student's $t$ test, whereas categorical variables were compared by using the $\chi^{2}$ test or Fisher's exact test, whenever appropriate. The relationships between clinical information at baseline (age, sex, ECG findings, presenting symptoms, and therapeutic modalities) and adverse cardiac outcomes were assessed by utilizing $\chi^{2}$ test. The statistically significant variables with a $p$ value $<0.05$ were further analyzed by multivariable logistic regression to find out the independent risk factors associated with adverse cardiac outcomes. Odds ratios (ORs) with 95\% confidence intervals (CIs) were computed. A $p$ value of $<0.05$ was considered to be statistically significant.

\section{Results}

A total of 153 patients reported by 140 separate case reports were included. Demographic and clinical features of the subjects are summarized in Table 1. In this study, the earliest diagnosis of IERA was established at the eighteenth week of gestation by fetal echocardiography $[1,10$, $11]$, and the oldest case reported was a 77-year-old male [12]. The mean age at diagnosis was $4.56 \pm 5.38$ years in the child group, which consisted of 70 patients. Among them, 29 patients were diagnosed prenatally. The adult group comprised 83 patients, the mean age at diagnosis being $42.83 \pm 17.37$ years. Patients' age profile is shown in Figure 1, and the condition was mostly diagnosed in the first decade of life. The 2 groups showed a slight male predominance.

About one-fifth of the IERA patients presented because of the finding during antenatal diagnosis, especially in the children group, while nearly half presented due to development of symptoms, especially in the adult group. The difference in the rate was statistically significant between the 2 groups $(p<0.001)$. The other patients presented after an incidental finding of cardiomegaly on chest radiography or health checkups.

Almost more than half of the patients clinically presented with a wide range of symptoms, without difference in incidence between the child and adult groups $(p=$ 0.221). Arrhythmia, dyspnea, and palpitation were the most common clinical presentations, followed by edema, chest discomfort, and fatigue.

ECG data were available in 148/153 patients and about half of them had abnormal findings. In all affected patients, supraventricular arrhythmias, including supraventricular tachycardia, atrial fibrillation $(\mathrm{AF})$, and atrial flutter, were more common (65/77). The incidence of abnormal ECG findings was not significantly different between the child and adult groups $(p=0.090)$. However, AF or atrial flutter events were significantly more frequent in the adult group ( $p=0.016)$.

The most common complication of IERA was arrhythmia, followed by embolism, and right heart failure (RHF). Only a few patients had a history of cerebral $(n=1)$ or peripheral embolic events $(n=2)$. Altogether 13 patients had the thrombus formation within the enlarged RA [1317]. Sudden cardiac death was reported in 6 patients, primarily due to refractory arrhythmia or RHF except 2 who died because of other associated anomalies [14, 18-22]. Altogether 6 patients developed tricuspid regurgitation, and 1 child had RA wall dissection [23]. Congenital IERA is often an isolated entity, and about one-fourth of patients were accompanied with other anomalies, with the most frequent being patent foramen ovale and atrial septal defect (Table 2). 


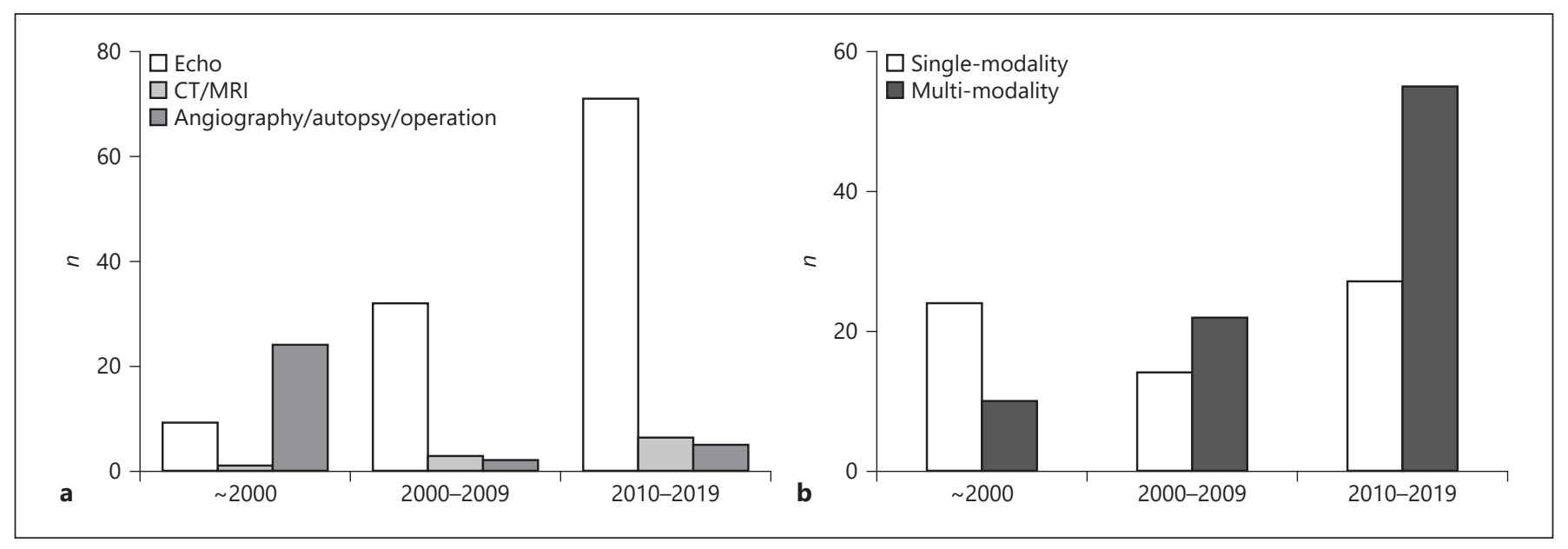

Fig. 2. Diagnostic technology (a) and imaging modality (b) of patients with IERA over a period of 2 centuries. IERA, idiopathic enlargement of the right atrium.

Table 2. Associations with other anomalies in IERA patients $(n=$ 153)

\begin{tabular}{lc}
\hline & Total \\
\hline Isolated IERA, $n(\%)$ & $116(75.82)$ \\
Cardiac anomalies, $n(\%)$ & $37(24.18)$ \\
Patent foramen ovale & $16(10.46)$ \\
Atrial septal defect & $14(9.15)$ \\
Patent ductus arteriosus & $3(1.96)$ \\
Ventricular septal defect & $2(1.31)$ \\
Pericardial effusion & $2(1.31)$ \\
Tricuspid dysplasia & $2(1.31)$ \\
Pulmonary valvar stenosis & $1(0.65)$ \\
Coronary anomalies & $1(0.65)$ \\
Cardiac dextrorotation & $1(0.65)$ \\
Sinus of Valsalva aneurysm & $1(0.65)$ \\
Hypertrophic cardiomyopathy & $1(0.65)$ \\
Cardiac amyloidosis (AL phenotype) & $1(0.65)$ \\
Left atrial appendage aneurysms & $1(0.65)$ \\
Noncardiac anomalies, $n$ (\%) & $2(1.31)$ \\
Abdominal aortic aneurysm & $1(0.65)$ \\
Progressive familial intrahepatic cholestasis & $1(0.65)$ \\
\hline
\end{tabular}

IERA, idiopathic enlargement of the right atrium.

The diagnosis of IERA is based on 2 essential criteria. The first is the disproportionate enlargement of RA compared to the other cardiac chambers. The second is the exclusion of all cardiovascular lesions producing right atrial enlargement [10]. Before 2000, an accurate assessment or diagnosis of this disease was accomplished through selective cardiac catheterization, electrophysio- logical studies, autopsy and surgery. Since then, transthoracic echocardiography is the most valuable tool for accurately diagnosing the lesion, and the multi-modality imaging approaches are commonly applied (Fig. 2).

Chest radiographic data in 105 patients revealed cardiomegaly with marked prominence of the right border in all except 1 patient who exhibited no abnormalities, and the diagnosis of IERA was intraoperatively established [24]. Transthoracic echocardiography was performed in 123 cases with alternative modalities such as fetal, transesophageal, and contrast echocardiography with the correct diagnosis of IERA in 111 patients. CT and CMRI were carried out in 47 and 41 patients, respectively, and both detected IERA in all the patients. These imaging studies were performed to further evaluate and/ or confirm the echocardiographically diagnosed IERA. Cardiac catheterization and electrophysiological studies were conducted in 48 patients to confirm the presence of an enlarged RA with a normally placed tricuspid and exclude any further cardiac anomalies associated with RA dilatation, such as cardiac shunts, pulmonary hypertension, obstructions to right atrial emptying, and Ebstein's anomaly. It is currently used less frequently given the improved quality and availability of other noninvasive imaging modalities.

Regardless of the imaging modality selected, IERA is commonly shown as a disproportionately enlarged RA with low blood velocity and spontaneous contrast within the cavity, usually occupying the entire anterior surface of the heart. Tricuspid valve anatomy and the remaining intracardiac structure are normal $[1,4,9,25,26]$ (Fig. 3, 
Fig. 3. a An apical 4-chamber transthoracic echocardiogram demonstrates a giant RAA arising from the right atrial free wall. b Color Doppler reveals a normally functioning tricuspid valve without obstruction. c, d Cardiac MRI confirms the giant RAA. RAA, right atrial aneurysm; LA, left atrium; LV, left ventricle; RA, right atrium; $\mathrm{RV}$, right ventricle.
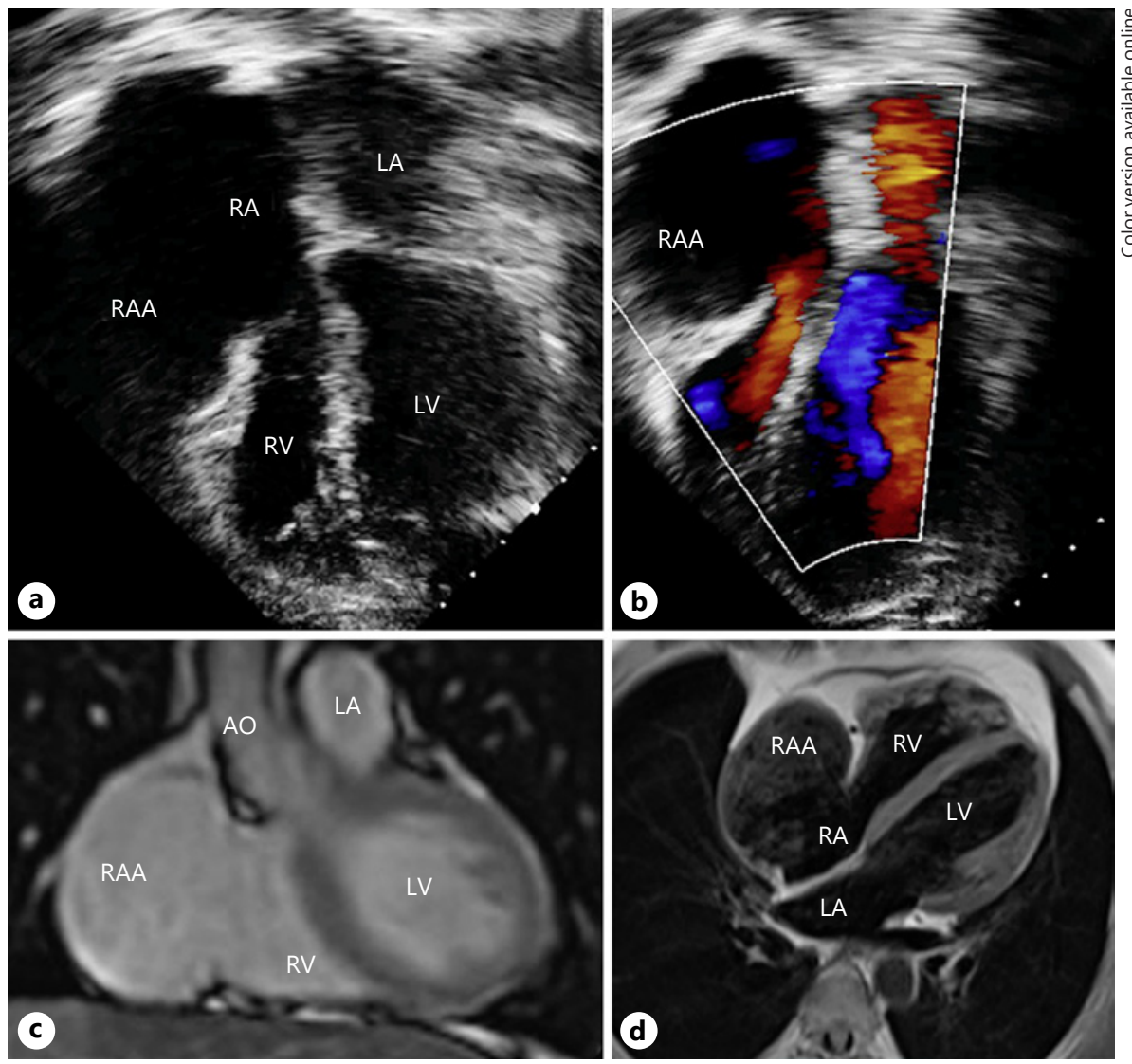

4). The size of the dilated RA varied considerably. The largest RA (sized $19.5 \times 15.2 \mathrm{~cm}$ ) was found in a 26-yearold patient by Ostovan et al. [27].

Histological specimens of resected right atria were available in 50 patients. Macroscopic examination described the atrium as paper-thin, translucent, and free of musculature. Microscopic examination revealed a wide array of histological changes ranging from severe subendocardial fibroelastosis and/or epicardial fibrosis $(n=$ 37 ), irregular reduction of the musculature involving elements $(n=40)$, lipomatous degeneration $(n=9)$, lymphocytic infiltration $(n=5)$, to entirely normal atrial tissue $(n=6)$. The typical pathological change is attenuated muscle fibers with epicardial fibrosis and endocardial fibroelastosis [28-30]. Data on the treatment modalities and follow-up were available for 144 patients. Follow-up duration ranged from 1 week to 23 years (mean time: $38.71 \pm 62.32$ years). Altogether 26 patients had adverse cardiac events, mainly related to IERA (Table 3 ).

Surgical resection of IERA was performed in 77 patients, including 43 juveniles and 34 adults. Among them, 20 asymptomatic patients underwent preventive resec- tion of the IERA, and the postoperative courses were uneventful in all except a 6-week-old child who developed severe tricuspid regurgitation [1]. The other 57 patients received RA resection because of the presenting symptoms. The postoperative courses were smooth in 48 patients, while 9 reported adverse cardiac events. Antiarrythmic, thrombo-prophylactic, and/or symptomatic medications were administered in 42 patients, including 15 children and 27 adults, who were mostly symptomatic $(n=29)$. Among them, 19 patients responded to the treatment while 10 failed to. Of the 10 refractory cases, 3 suffered sudden cardiac death, mainly due to refractory atrial tachycardia or RHF. Altogether 22 asymptomatic patients and 3 symptomatic adults received no special therapy, including 11 children and 14 adults.

No significant differences existed between the child and adult groups in the treatment modalities and the incidence of adverse events $(p>0.05)$. Univariate $\chi^{2}$ test showed ECG findings, presenting symptoms, and therapeutic modalities being significantly correlated with the adverse outcomes of IERA. Multivariate logistic regression revealed a significant association of the presenting
92

Cardiology 2021;146:88-97 DOI: $10.1159 / 000511434$
Zhang/Zhang/He/Li/Li/Zhang/Xie 

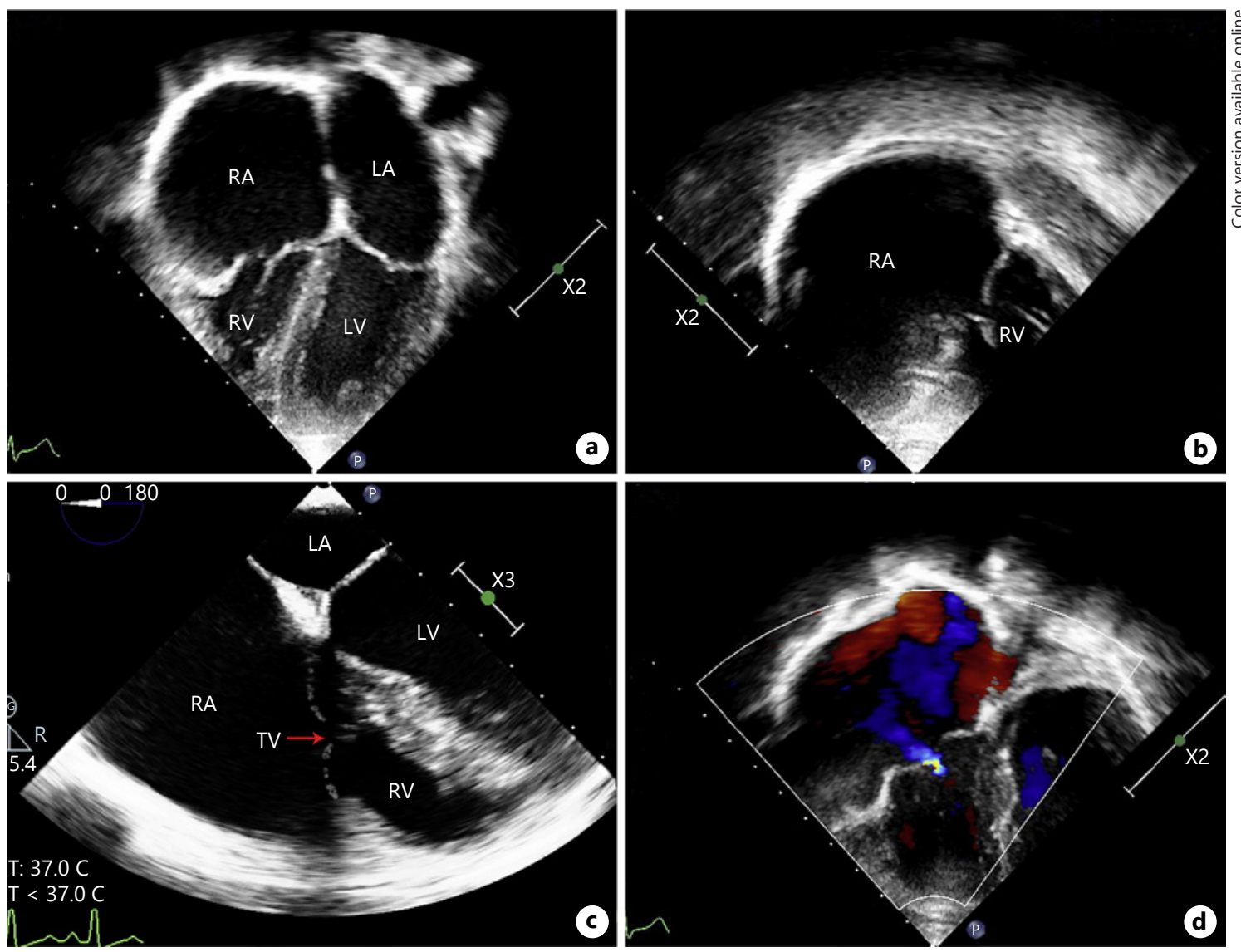

Fig. 4. a, b Transthoracic echocardiography at apical 4-chamber view (a) and right ventricular inflow view (b) demonstrates a remarkably enlarged RA with a normally placed tricuspid. c Transesophageal echocardiography confirms the diagnosis of IERA. d Color Doppler reveals a mild TR. LA, left atrium; LV, left ventricle; RA, right atrium; RV, right ventricle; TV, tricuspid valve; TR, tricuspid regurgitation.

symptoms with poor outcomes $(\mathrm{OR}=6.587,95 \% \mathrm{CI}$ $[1.054,41.172], p=0.044)$, and conservative treatment was more associated with poor outcomes compared to surgical resection $(\mathrm{OR}=2.994,95 \% \mathrm{CI}[1.228,7.302], p=$ 0.016) (Table 4).

\section{Discussion}

IERA is a rare abnormality of unknown etiology and was first described by Bailey in 1955 [24]. Whether it is an acquired or a congenital condition remains at issue. The predominance of juvenile cases and diagnoses at a young age in the adult cases are suggestive of its congenital nature $[3,14,30,31]$. Some researchers speculated that an intrinsic structural protein deficiency, abnormal collagen, or dysplastic pectinate muscles might subject the RA to dilatation $[2,4,13,24]$. Prenatal $[1,10,32]$ and familial [14] cases were reported, although familial IERA is rare. The aneurysm or diverticulum was either single or multiple [13, 25, 33]. There appears to be no link between the development of the disease and age. This study also showed that the age of the patients at diagnosis ranged from 18 weeks of gestation to 77 years. The wide age range suggests IERA as a phenotypic syndrome rather than a separate disease entity [14].

Estimation of the true incidence of the condition is challenging, as some patients remain asymptomatic even at advanced age, leading to missed diagnosis. With asymptomatic individuals, this cardiac anomaly is usually found by accident as cardiomegaly on a routine chest radiograph or by fetal echocardiography $[30,34]$. When symptoms become apparent, they vary considerably. This review, for the first time, demonstrated that the develop- 
Table 3. Adverse clinical outcomes reported in the literature

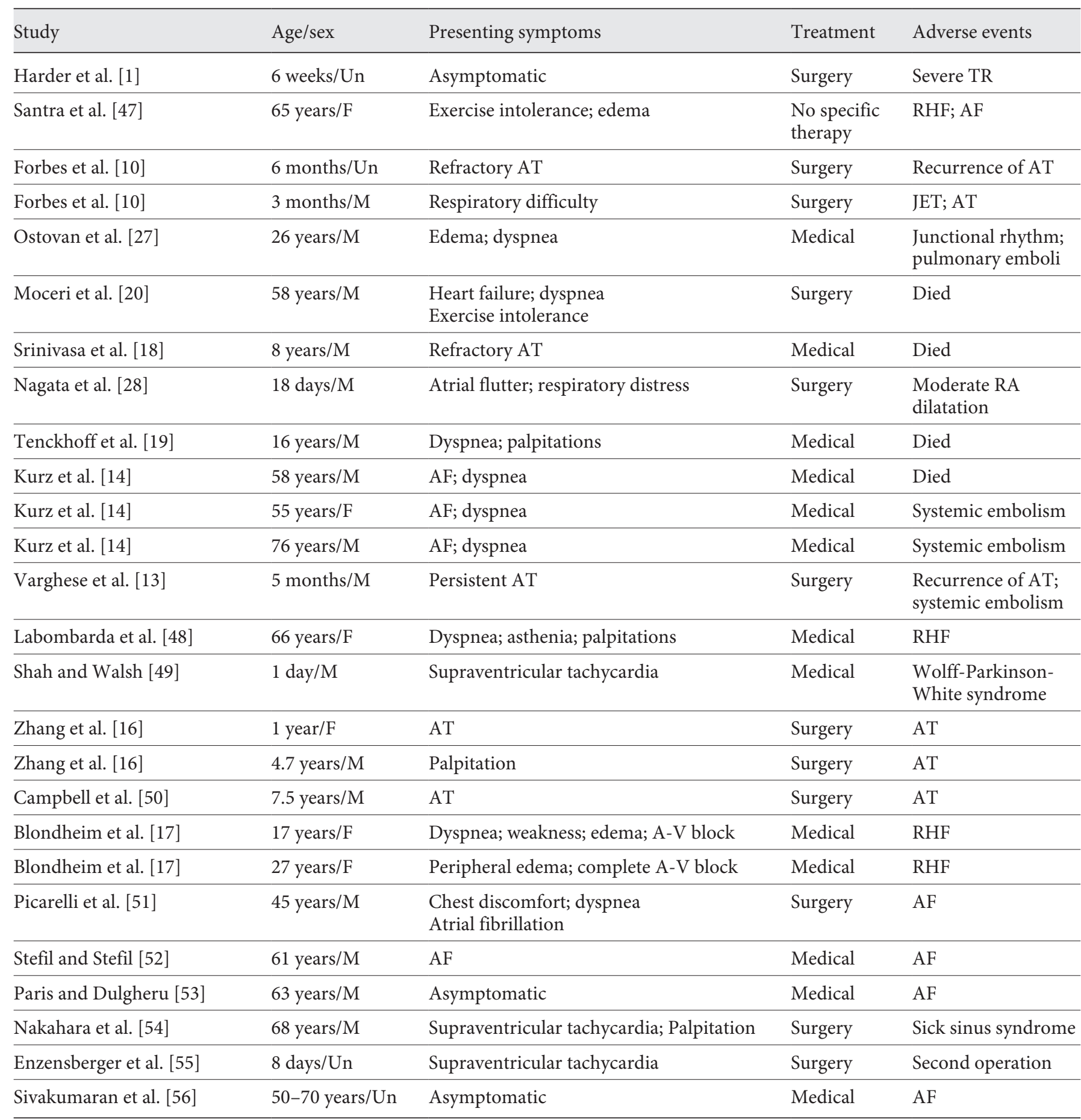

TR, tricuspid regurgitation; RHF, right heart failure; AF, atrial fibrillation; AT, atrial tachycardia; JET, junctional ectopic tachycardia; RA, right atrial; A-V block, atrio-ventricular block. 
Table 4. Factors associated with adverse clinical outcomes $(n=142)$

\begin{tabular}{|c|c|c|c|c|c|c|}
\hline Variable & $\begin{array}{l}\text { Adverse } \\
\text { events } \\
(n=26)\end{array}$ & $\begin{array}{l}\text { Uneventful } \\
\text { outcomes }\end{array}$ & \multicolumn{2}{|c|}{ Univariate $\chi^{2}$ test } & \multicolumn{2}{|c|}{ Multivariate logistic regression } \\
\hline \multicolumn{7}{|l|}{ Age } \\
\hline Adult & 13 & 61 & 0.057 & 0.811 & 1.00 & 0.206 \\
\hline Child & 13 & 55 & & & $0.538(0.206-1.406)$ & \\
\hline \multicolumn{7}{|l|}{ Sex } \\
\hline M & 16 & 68 & & & $1.729(0.721-4.146)$ & \\
\hline Un & 4 & 9 & & & & \\
\hline \multicolumn{7}{|l|}{ Presenting symptoms } \\
\hline $\mathrm{N}$ & 3 & 52 & 9.918 & 0.002 & 1.00 & 0.044 \\
\hline $\mathrm{Y}$ & 23 & 64 & & & $6.587(1.054-41.172)$ & \\
\hline \multicolumn{7}{|l|}{ ECG findings } \\
\hline No specific therapy & 1 & 23 & & & $1.975(0.305-12.805)$ & \\
\hline Medical & 13 & 27 & & & $2.994(1.228-7.302)$ & 0.016 \\
\hline
\end{tabular}

ment of clinical symptoms, the incidence of arrhythmia, and the therapeutic modalities of the condition bore no significant relation to age, whereas the development of complications varied with age. Less than half of the patients in the child group showed complications at diagnosis, while most adult patients developed complications, mainly including embolism and RHF. This discrepancy might be attributed to the demographic differences among the subjects since the subjects in the child group had a short course. Some cases were diagnosed or identified antenatally, shortly after delivery or at early infancy due to advances in imaging technologies and growing application of fetal echocardiography for the screening of congenital diseases.

Some researchers believe IERA as a benign condition not affecting life expectancy [7,35], but others suggested its complications were life-threatening, including refractory arrhythmias, RHF, thromboembolic events, and sudden death $[6,34,36]$. This review found 4 sudden cardiac deaths due to refractory atrial tachycardia or RHF in 153 IERA patients. The most common complications were supraventricular arrhythmias, such as AF, atrial flutter, and supraventricular tachycardia. The precise underlying mechanism for arrhythmias in IERA patients is not fully understood. The atrial tissue per se might contribute to the development of arrhythmias, either by providing a broad surface rendering circular movements possible or by developing irritable ectopic foci, or by being prone to atrial re-entry tachycardia [24,36-38], since arrhythmia responds only to surgical treatment.

Since IERA is rare, it can be mistaken for other anomalies leading to RA enlargement, such as Ebstein's anomaly, partial anomalous pulmonary vein return, pericardial cyst, or cardiac tumors. Multiple imaging modalities are currently available [39-41] and chest radiographical examination can reveal a cardiac malformation. Nonetheless, such malformation cannot be definitively diagnosed by this technique alone. Transthoracic echocardiography can diagnose the condition. At times, it is hard to distinguish between atrial aneurysm and contiguous cardiac tumors. Transesophageal echocardiography, contrast echocardiography, CT, and cardiac MRI might assist in its diagnosis $[34,42]$.

So far, no consensus has been reached over the treatment of IERA. The probable options for IERA and associated complications include surgical resection, follow-up with conservative treatment, and watchful waiting without medical intervention [4, 7]. For asymptomatic patients, some clinicians suggested prophylactic resection to avert possible complications $[4,26,43,44]$. Others, however, suggested a watchful waiting in combination with regular follow-up [6]. Some patients responded well to the surgical treatment while others were more responsive to the nonsurgical approach $[3,10]$. In this study, we 
attempted to identify the risk factors associated with prognosis in IERA patients and presenting symptoms, positive ECG findings, and therapeutic modalities were found related to adverse cardiac outcomes. Moreover, symptomatic patients were significantly more likely to have poor outcomes than asymptomatic patients. Compared with surgical resection, conservative treatment was more often associated with poor outcomes. These results indicated that presenting symptoms and treatment modalities may be independent risk factors for adverse cardiac outcomes. Accordingly, we suggested that surgical intervention should be considered for symptomatic patients. Consistent with our findings, other authors held the same notion $[1,33,45,46]$.

Interestingly, our study also showed that, compared with surgical resection, watchful waiting without medical intervention was not associated with the higher risk for adverse cardiac outcomes. This could be due to the demographic differences among the subjects since those who received no special intervention were virtually asymptomatic compared with their counterparts subjected to surgical resection. Moreover, long-term regular followup, instead of thromboprophylaxis, prophylactic antiarrhythmic treatment, or prophylactic surgery, might be the best management strategy for asymptomatic patients. The latter have not been proven to be useful before the onset of the symptom or development of complications. However, this warrants further confirmation in further longitudinal studies and the correlation of severity of the clinical picture with the degree of atrial enlargement which remains unanswered in our study requires future research.

\section{Conclusion}

In this study, we conducted a systematic review on IERA and showed that although rare, it is associated with potential life-threatening complications and sudden cardiac death. Echocardiography is the most commonly used diagnostic modality. Surgical resection is indicated for symptomatic IERA.

\section{Conflict of Interest Statement}

The authors have no conflicts of interest to declare.

\section{Funding Sources}

This research was supported by the Natural Science Foundation of Hubei Province (No. 2019CFB719).

\section{Author Contributions}

Conceptualization and supervision: Li Zhanga,b and Mingxing Xie. Project administration: Jing Zhang and Mingxing Xie. Literature search and data curation: Jing Zhang, Li Zhang ${ }^{c}$, and He Li. Formal analysis, investigation, and methodology: Jing Zhang, Lin $\mathrm{He}$, and Yuman Li. Software and writing - original draft: Jing Zhang. Writing - review and editing: Yuman Li and Li Zhang,b.

\section{References}

1 Harder EE, Ohye RG, Knepp MD, Owens ST. Pediatric giant right atrial aneurysm: a case series and review of the literature. Congenit Heart Dis. 2014 May/Jun;9(3):E70-7.

2 Uppu SC, Sachdeva R, Imamura M. Idiopathic giant right atrial aneurysm. Ann Pediatr Cardiol. 2013 Jan-Jun;6(1):68-70.

3 Chatrath R, Turek O, Quivers ES, Driscoll DJ, Edwards WD, Danielson GK. Asymptomatic giant right atrial aneurysm. Tex Heart Inst J. 2001;28(4):301-3.

4 Lee Y, Cho J, Kim G, Lee S, Hyun M, Kim Y. Surgical repair of giant right atrial aneurysm in a neonate. Korean Circ J. 2011 Jun;41(6): 331-3.

5 Binder TM, Rosenhek R, Frank H, Gwechenberger M, Maurer G, Baumgartner H. Congenital malformations of the right atrium and the coronary sinus: an analysis based on 103 cases reported in the literature and two additional cases. Chest. 2000 Jun;117(6):1740-8.

6 Bezuska L, Bu'Lock FA, Anderson RH, Speggiorin S, Corno AF. Giant right atrial aneurysm: antenatal diagnosis and surgical treatment. World J Pediatr Congenit Heart Surg. 2016 May;6(9):1-4.

7 Hofmann SR, Heilmann A, Häusler HJ, Dähnert I, Kamin G, Lachmann R. Congenital idiopathic dilatation of the right atrium: antenatal appearance, postnatal management, longterm follow-up and possible pathomechanism. Fetal Diagn Ther. 2012 Dec;32(4):256-61.

8 Surace FC, Iezzi F, Colaneri M, Pozzi M. Surgical treatment of idiopathic enlargement of the right atrium. Case Rep Surg. 2018;20: 7241309 .
9 Chockalingam A, Alagesan R, Gnanavelu G Dorairajan S, Subramaniam T. Right atrial aneurysm in adults: report of three cases and review of literature. Echocardiography. 2004 Oct;21(7):639-43.

10 Forbes K, Kantoch MJ, Divekar A, Ross D, Rebeyka IM. Management of infants with idiopathic dilatation of the right atrium and atrial tachycardia. Pediatr Cardiol. 2007 Aug;28(4):289-96.

11 Özyurt A, Baykan A, Argun M, Pamukçu Ö, Mavili E, Narin N. Spontaneously regressed congenital idiopathic dilatation of the right atrium in the newborn. Anadolu Kardiyol Derg. 2014 Feb;14(1):90-2.

12 Funabashi N, Sekine T, Komuro I. Idiopathic diverticulum-type enlargement of the right atrium demonstrated by multislice computed tomography. Heart. 2006 Aug;92(8):1144. 
13 Varghese PJ, Simon AL, Rosenquist GC, Berger M, Rowe RD, Bender HW. Multiple saccular congenital aneurysms of the atria causing persistent atrial tachyarrhythmia in an infant. Report of a case successfully treated by surgery. Pediatrics. 1969 Oct;44(3):42933.

14 Kurz DJ, Oechslin EN, Kobza R, Jenni R. Idiopathic enlargement of the right atrium: 23 year follow up of a familial cluster and their unaffected relatives. Heart. 2004 Nov;90(11): $1310-4$.

15 Pawar RS, Tiwari A, Suresh PV, Raj V, Kaushik P. A case of giant right atrial aneurysm in a child. World J Pediatr Congenit Heart Surg. 2016 Feb;7(4):516-9.

16 Zhang Y, Li XM, Jiang H, Jin YQ, Zhang FQ, Liu HJ, et al. Right atrial appendage aneurysm resection to cure aneurysm-related atrial tachyarrhythmia. Pediatr Cardiol. 2019 May; 40(6):1144-50.

17 Blondheim DS, Klein R, Plich M, Marmor AT. Familial idiopathic dilatation of the right atrium with complete atrio-ventricular block: a new syndrome? Cardiology. 2000 April; 94(4):224-6.

18 Srinivasa KH, Kharge J, Patil S, Rangan K, Ramalingam R. Idiopathic dilatation of the right atrium: clinical and diagnostic pitfalls: a series of 3 cases. Echocardiography. 2013 Sep;30(8): 984-8.

19 Tenckhoff L, Stamm SJ, Beckwith JB. Sudden death in idiopathic (congenital) right atrial enlargement. Postmortem findings and review of cases. Circulation. 1969 Aug;40(2): $227-35$.

20 Moceri P, Berkane N, Checler C, Chiche O, Ferrari E. Giant congenital right atrium: a very rare entity diagnosed in an adult patient. Int J Cardiol. 2013 Jun;166(2):e36-7.

21 Vilacosta I, San Román JA, Camino A, Zamorano J, Javier Cortés F, Sánchez Harguindey L. Right atrial diverticulum and hypertrophic cardiomyopathy. Eur Heart J. 1993 May; 14(5):721-2.

22 Mersbach K, Mehra A, Jaworski J, Fyfe B. Nonseptal right atrial aneurysm: case report and review of literature. Cardiovasc Pathol. 2010 May-June;19(3):e79-83.

23 Zhang J, He L, Wang T, Li Y, Wang L, Zhang $\mathrm{L}$, et al. Spontaneous right atrial dissection and congenital right atrial aneurysm. Ann Thorac Surg. 2018 Mar;106(1):e29-31.

24 Zeebregts CJ, Hensens AG, Lacquet LK. Asymptomatic right atrial aneurysm: fortuitous finding and resection. Eur J Cardiothorac Surg. 1997 April;11(3):591-3.

25 Venugopalan P, Jain R. Accidental detection of a giant right atrial aneurysm in an asymptomatic infant. Acta Cardiol. 2002 May;57(2): $125-7$.
26 Papagiannis J, Chatzis A, Sarris G. Giant right atrial aneurysm: a case report. Int J Cardiol. 2008 Sep;129(1):e5-6.

27 Ostovan M, Shahrzad S, Taban S, Moniri A. Idiopathic right atrial enlargement. Asian Cardiovasc Thorac Ann. 2013;21(6):717-9.

28 Nagata H, Stambach D, Wilson GJ, Menon A, Jaeggi E. Fetal diagnosis of right atrial aneurysms. Can J Cardiol. 2016;32(10):1260.e11-

29 Tunks RD, Malysz J, Clark JB. Neonatal management of a giant right atrial appendage aneurysm. Circulation. 2015;132(19):e226-8.

30 Gomes S, Wolfenden H, Lambros J. Giant right atrium in an adult: case report of a rare condition. Heart Lung Circ. 2012;21(1):50-2.

31 Jeserich M, Kirchberger J, Geibel A. Idiopathic dilatation of the right atrium in a female adult. Clin Res Cardiol. 2008;97(2):131-4.

32 Bhupali AN, Patankar KB, Paranjpe FS, Tamhane AU. Giant right atrium in a foetus. Indian Heart J. 2013;65(4):493-5.

33 Miyamura H, Nakagomi M, Eguchi S, Aizawa Y. Successful surgical treatment of incessant automatic atrial tachycardia with atrial aneurysm. Ann Thorac Surg. 1990;50(3):476-8.

34 Navabi MA, Kiani A, Shabanian R. Congenital right atrial aneurysm in an infant. Pediatr Cardiol. 2008;29(5):998-9.

35 Blaysat G, Villain E, Marcon F, Rey C, Lipka J, Lefevre M, et al. Prognosis and outcome of idiopathic dilatation of the right atrium in children. A cooperative study of 15 cases. Arch Mal Coeur Vaiss. 1997;90:645-8.

36 Jonavicius K, Lipnevicius A, Sudikiene R, Zurauskas E, Lebetkevicius V, Tarutis V. Surgical repair of a giant congenital right atrial aneurysm: a case report. J Cardiothorac Surg. 2015;10:72.

37 Koželj M, Angelski R, Pavcnik D, Zorman D. Idiopathic enlargement of the right atrium. Pediatr Cardiol. 1998;19(5):420-1.

38 Masuda S, Saiki Y, Itoh K, Sadahiro M. Surgical treatment of congenital right atrial aneurysm in an adult patient. Jpn J Thorac Cardiovasc Surg. 2004;52(5):254-6.

39 da Silva Castro A, Ferreira N, Ferraz R, Bettencourt N, Mota JC, Gama Ribeiro V. A rare case of congenital aneurysm of the right atrium. Rev Port Cardiol. 2014;33(9):571-2.

40 Imren Y, Halit V, Kula S, Olgunturk R. Giant right atrial aneurysm: case report. Int J Cardiol. 2006;112(3):e66-8.

41 Yukiiri K, Mizushige K, Ohmori K, Wada Y, Tanimoto K, Ueda T, et al. Contrast transesophageal echocardiography in diagnosing congenital enlargement of the right atrium - a case report. Angiology. 2003;54(5):619-23.
42 Scalia GM, Stafford WJ, Burstow DJ, Carruthers T, Tesar PJ. Successful treatment of incessant atrial flutter with excision of congenital giant right atrial aneurysm diagnosed by transesophageal echocardiography. Am Heart J. 1995;129(4):834-5.

43 Zaqout M, De Wolf D. Congenital giant aneurysm of the right atrium. Anadolu Kardiyol Derg. 2011;11(8):E34.

44 Marin-Garcia J, Allen RG. Idiopathic dilatation of the right atrium: postoperative followup in a child. J Pediatr Surg. 1983;18(2):1968.

45 Huang Z. Repair of idiopathic dilatation of the right atrium. J Card Surg. 2014;29(4):4824.

46 Rajbanshi BG, Phillips SD, Burkhart HM. Minimally invasive surgical resection of right atrial aneurysm. J Am Coll Cardiol. 2011; 58(23):e41.

47 Santra G, Paul R, Das S, Datta A, Pradhan S, Sarkar RN. Congenital giant right atrium in an elderly woman. J Assoc Physicians India. 2014;62(7):634-6.

48 Labombarda F, Mery C, Maragnes P. Idiopathic dilatation of the right atrium. Eur Heart J Cardiovasc Imaging. 2012;13(4):291.

49 Shah K, Walsh K. Giant right atrial diverticulum: an unusual cause of Wolff-ParkinsonWhite syndrome. Br Heart J. 1992;68(1):589.

50 Campbell RM, Parks WJ, Crawford FA, Gillette PC. Right atrial diverticulum presenting as Wolff-Parkinson-White syndrome. Pacing Clin Electrophysiol. 1992;15(8):1101-4.

51 Picarelli D, Dodera A, Antunez S, Touyá G, Abdala D. Extensive atrial wall resection in a patient with symptomatic idiopathic right atrial enlargement. J Thorac Cardiovasc Surg. 2005;130(4):e3-4.

52 Stefil M, Stefil S. Late presentation of right atrial diverticulum: surgical intervention might not be imperative. Eur Heart J Cardiovasc Imaging. 2019;20(12):1432.

53 Paris C, Dulgheru RE. Idiopathic enlargement of the right atrium. Acta Cardiol. 2019; 74(2):171-2.

54 Nakahara T, Minakata K, Yamazaki K, Funamoto M, Sakata R. Bilateral atrial appendage aneurysms associated with atrial fibrillation. Asian Cardiovasc Thorac Ann. 2014;22(3): 347-9.

55 Enzensberger C, Kreymborg KG, Valeske K, Apitz C, Akintürk H, Schranz D, et al. Management of idiopathic giant dilatation of the right atrium with subsequent atrial tachycardia. Arch Gynecol Obstet. 2013;288(3):705-7.

56 Sivakumaran L, Sayegh K, Mehanna E, Sanchez FW, Fields J, Cury R. Use of cardiovascular magnetic resonance in the evaluation of a giant right atrial appendage aneurysm: a case report and review of the literature. BMC Res Notes. 2017;10(1):681. 